\title{
Reference values for peak nasal inspiratory flow in children and adolescents in Brazil*
}

\author{
Cássio da Cunha Ibiapina ${ }^{1}$, Cláudia Ribeiro de Andrade ${ }^{1}$, Paulo Augusto \\ Moreira Camargos ${ }^{1,2}$, Cristina Gonçalves Alvim ${ }^{1}$, Álvaro Augusto Cruz ${ }^{3}$ \\ 1 Department of Pediatrics, Pediatric Pulmonology Unit, Universidade Federal de Minas Gerais, \\ Belo Horizonte, Brazil \\ 2 Senior Visiting Professor, Universidade Federal de São João Del Rey, and Pediatric \\ Pulmonology Unit, University Hospital, Universidade Federal de Minas Gerais, Brazil. \\ 3 ProAR, Faculdade de Medicina da Bahia, Universidade Federal da Bahia, Salvador, Brazil
}

SUMMARY

Statement of the problem: Allergic rhinitis is a global public health issue. Peak nasal inspiratory flow (PNIF) can help in the assessment of patients with allergic rhinitis. However, reference values in the literature for PNIF in school children and adolescents are limited.

The aim of this study was to identify reference values of PNIF among children and adolescents.

Methods: We conducted a cross-sectional study to identify reference values of PNIF among healthy school children and adolescents aged from eight to fifteen years old, selected from 14 randomly selected public schools. Participants performed measurements of PNIF using the In-check-inspiratory flow meter (Clement Clarke, Harlow, England). PNIF values were correlated to gender, age, height, weight and body mass index.

Results: A total of 526 subjects participated in the study. The final linear regression model for PNIF allowed obtaining the following equation for subjects aged from eight to 15 years old: PNIF $(\mathrm{l} / \mathrm{m})=$ height (centimeters) $\times 0.7+11.2$, for boys and PNIF $(\mathrm{l} / \mathrm{m})=$ height (centimeters) $x$ 0.7, for girls.

Conclusion: the equations of the final regression model resulted in a simple formula to obtain reference values of PNIF for subjects aged from 8 to 15 years old.

Key words: age, allergic rhinitis, peak nasal inspiratory flow, reference values

\section{INTRODUCTION}

Allergic rhinitis is a global public health problem ${ }^{(1)}$. It is one of the most common chronic diseases ${ }^{(2)}$ and is one of the most common reasons of access to the primary health care services (3). The diagnosis of allergic rhinitis usually relies on anamnesis and physical examination. Clinical scores can be useful in subsequent assessments. As patients may underestimate the severity of nasal obstruction ${ }^{(4,5)}$, objective measures are desirable for the initial evaluation of the severity of the nasal airflow obstruction and for follow-up. Among others, the methods currently available for this purpose are rhinomanometry, acoustic rhinometry, and peak nasal inspiratory flow (PNIF) ${ }^{\left({ }^{6}\right.}$. However, rhinomanometry and acoustic rhinometry are somewhat complex and therefore rarely used in clinical practice. In general, these measurements are commonly carried out by otolaryngologists ${ }^{(7,8)}$. They demand more complex and expensive standardized techniques and equipment than those that measure PNIF ${ }^{(9,10)}$. Rhinomanometry and PNIF measurements of nasal airflow obstruction have been proven to correlate well, with coefficients that range between 0.35 and $0.63(\mathrm{p}<0.05)^{(11-13)}$. Such findings are of major interest to practicioners as the PNIF measurement is a quick, simple and low-cost method that can be performed in the office in primary health care settings.

In the adult population, Ottaviano et al. ${ }^{(14)}$ established curves with normal variation, as they assessed 137 adults aged 16 to 84 years without nasal problems and provided charts correlating age, height, and gender with PNIF. Some studies have looked at reference values for PNIF in the pediatric population. In a pilot study, Prescott and Prescott reported curves that correlated age, weight, and height with the value of PNIF, after assessing 102 children between six months and eight years of age ${ }^{(15)}$. More recently, Papachristou et al. evaluated 3170 Greek children and adolescents and found that PNIF accorded to age and sex ${ }^{(16)}$. However, no multivariate analysis was conducted by the authors to correct the associations according to the effects of all variables on PNIF and reduce confounding.

The present study was carried out to identify PNIF reference values in children and adolescents, aiming to facilitate the use and interpretation of this tool that provides an objective indicator that can contribute to better assessment and control of chronic rhinitis. 


\section{MATERIALS AND METHODS}

Design, population, setting, and period of the study

This is a cross-sectional study carried out in 14 randomly selected public schools in Belo Horizonte City, Brazil, between April 2008 and February 2009. The population studied was made up of school children and adolescents aged 8 to 15 years old, of mixed ethnicity.

\section{Ethics}

The study protocol and the written informed consent were approved by the Committee of Ethics in Human Research of the Federal University of Minas Gerais.

\section{Inclusion and exclusion criteria}

Healthy children and adolescents with no symptoms of chronic rhinitis or asthma according to the ISAAC ${ }^{(1)}$ questionnaire on asthma and allergic rhinitis were included. Subjects found to have adenoid hypertrophy, bacterial sinusitis, deviated septum, nasal polyps, upper respiratory tract infection and those unable to perform the maneuver to obtain PNIF were excluded, upon the initial evaluation by a pediatrician.

\section{Clinical assessment}

Participants were assessed in school visits, during which questionnaires were filled out by the adolescents aged 12 years old or older. For younger students, questionnaires were filled out by their parents. We also collected data on gender, age, weight and height.

\section{Measurements}

Before PNIF measurements, participants performed a usual nasal hygiene routine, slightly blowing their noses. The facial mask was duly placed with participants standing up. They were then told to take a vigorous nasal inspiration from the residual capacity with their mouths closed until reaching their total pulmonary capacity. The device used was the in-check-inspiratory flow meter (Clement Clarke, Harlow, England) that provides measurements that range from 30 to $370 \mathrm{~L} / \mathrm{min}$. At least three measurements were taken and the highest value obtained was considered for analysis.

\section{Statistical analysis}

The sample size calculation was based on Student's-t-test, wherein the PNIF values for gender were compared using values obtained from a pilot study. To ensure a power of 0.80 and considering an alpha error of 0.05 , it was defined that a sample size of at least 126 participants would be necessary for each gender. To ensure greater sampling power, and based on the Central Limit Theorem, which settles that around 30 participants should provide rough approximations for practical applications and also considering the need to carry out sub-comparisons between the PNIF for age, a minimum of 30 participants for each sex and age was chosen.

For descriptive analysis, we calculated the frequencies and percentages for the characteristics of the various categorical variables and measures of central tendency (mean and median) and standard deviation for the continuous variables.

\section{Univariate analysis}

The comparison of PNIF according to the quantitative co-variables (age, height, weight and body mass index (BMI) $\mathrm{Z}$ score and percentile) was also based on Pearson's coefficient correlation.

In the comparison of the PNIF according to the gender, the Mann-Whitney test was used. Normal distribution of the data was verified by the Kolmogorov-Smirnov test.

The calculation of the height, weight and BMI Z score and percentile was made by the Epilnfo program, using the CDC 2000 curve.

\section{Multivariate analysis}

A linear regression model was developed, in which height was initially included, and subsequently all variables with p-value $\leq 0.25$ in the univariate analysis were included as well. After that, each of the variables were withdrawn in a stepwise process until the final model included only those reaching statistical significance ( $p$-value $\leq 0.05$ ). In addition, the interaction among all the co-variables present in the final regression model was tested.

\section{RESULTS}

The ISAAC questionnaires were handed out to 1500 school children and adolescents and the response rate was $82 \%$. Out of this total (1197), 671 were excluded (38.5\%) due to at least one positive answer to any question suggesting the diagnosis of chronic rhinitis and/or asthma. Thus, 526 school children and adolescents were assessed, $49.6 \%$ of whom were boys. Table 1 presents the descriptive characteristics of the studied population.

The mean age of the participants was 143.8 months, corresponding to 11.9 years of age. The average weight was $42.5 \mathrm{~kg}$ $( \pm 13.6)$.

\section{Univariate and multivariate analysis}

The average of the PNIF in boys was $111.6 \mathrm{~L} / \mathrm{min}(\mathrm{SD} \pm 38.2$ ) whereas in girls it was 99.2 L/min ( $\mathrm{SD} \pm 31.6), \mathrm{p}<0.01$.

There was a significant correlation between PNIF and age $(\mathrm{r}=0.228, \mathrm{p}<0.001)$, height $(\mathrm{r}=0.263, \mathrm{p}<0.001)$, weight $/$ age score $Z(r=0.104, p=0.017)$, and BMI score $Z(r=0.105$, $\mathrm{p}=0.016$ ). The co-variables with $\mathrm{p}$-value lower than 0.25 in the univariate analysis that were included in the selection step of the multivariate model were: gender, age, $\mathrm{Z}$ score, weight/ age, $\mathrm{Z}$ score BMI, percentile weight/age and percentile BMI.

The variables that remained in the final regression model were gender and height as presented in Table 2.

The equations of the final regression model are shown as the following formula, for boys and girls, respectively:

Predicted PNIF (boys), in liters/minute $=0.7 \mathrm{x}$ height (centimeters) $+11.2$

Predicted PNIF (girls), in liters $/$ minute $=0.7 \times$ height (centimeters) 
It can be noted that boys had, on average, a 11.2 liters minute higher PNIF than girls. The addition of one centimeter $(\mathrm{cm})$ in height causes the increase of approximately 0.7 liters/minute in the predicted PNIF, i.e., approximately 7.0 liters/minute per additional 10 centimeters.

Figures 1 and 2 display predicted mean values, upper and lower limits for PNIF according to height for boys and girls, respectively.

As shown, for boys and girls, the predicted mean values of PNIF increase with height and are higher in boys. For example, for a boy with a height of $134 \mathrm{~cm}$, the predicted value is $100 \mathrm{~L} / \mathrm{min}$, whereas for a girl with this height, the predicted value is approximately $90 \mathrm{~L} / \mathrm{min}$.

\section{DISCUSSION}

This study reports reference values of PNIF for subjects from 8 to 15 years old. To date, no reference values obtained from multivariate analysis have been identified in the literature for these age groups. In the population studied, a positive correlation was observed between measurements of PNIF, gender and height.

In younger children, Prescott and Prescott assessed 102 subjects between the ages of six months and eight years of age, selected in an ear-nose-throat (ENT) outpatient facility ${ }^{(15)}$. The criteria for admission were weight and height between the percentiles 25 and 75 and the absence of nasal symptoms. PNIF measures were obtained using an equipment built for this purpose, which recorded successive inspiratory efforts. In the studied population, an increase in PNIF was noticed with an older age, as the present study shows. For infants, PNIF average was $30 \mathrm{~L} / \mathrm{min}$ and for the eight year-olds the average was $80 \mathrm{~L} / \mathrm{min}$. Their observations were somewhat similar to those we describe in the present study: $96.0 \mathrm{~L} / \mathrm{min}( \pm 5.1)$ and $92.1 \mathrm{~L} / \mathrm{min}$ ( \pm 3.4$)$ for boys and girls, respectively. A linear correlation was also noted with height, age and weight, especially the former.

Table 1. Descriptive characteristics of the participants $(n=526)$.

\begin{tabular}{lcccc}
\hline Variable & Mean & SD & Minimum & Maximum \\
\hline Age (years) & 11,9 & 2,3 & 8 & 15 \\
Weight (kilo- & & & & \\
gram) & 42,5 & 13.6 & 18.0 & 96.0 \\
Height (cm) & 150.9 & 13.6 & 115.0 & 188.0 \\
Z Score & & & & \\
Weight/Age & -0.1 & 1.1 & -5.8 & 3.1 \\
Height/Age & 0.2 & 1.1 & -5.5 & 5.5 \\
BMI* & -0.3 & 1.3 & -7.5 & 2.8 \\
Percentile & & & & \\
Weight/Age & 48.4 & 30.1 & 0.0 & 99.9 \\
Height/Age & 54.8 & 29.4 & 0.0 & 99.9 \\
BMI & 44.6 & 31.8 & 0.0 & 99.7 \\
\hline
\end{tabular}

Table 2. Final regression model for Peak nasal inspiratory flow (PNIF).

\begin{tabular}{lccccc}
\hline \multirow{2}{*}{ Model } & \multirow{2}{*}{$\begin{array}{c}\text { Coefi- } \\
\text { cient }\end{array}$} & SE* & p-value & $\begin{array}{c}\text { Lower } \\
\text { limit }\end{array}$ & $\begin{array}{c}\text { Upper } \\
\text { limit }\end{array}$ \\
\hline Constant & -0.02 & 16.5 & 0.999 & -32.4 & 32.3 \\
Gender & & & & & \\
$\quad$ Male & 11.2 & 3.0 & $<0.001$ & 5.3 & 17.1 \\
Height $(\mathrm{cm})$ & 0.7 & 0.1 & $<0.001$ & 0.5 & 0.9 \\
\hline
\end{tabular}

*SE: standard error

In the adult population, Ottaviano et al. reported reference values of PNIF ${ }^{(14)}$. The authors assessed 137 healthy Caucasian volunteers between the ages of 16 and 84, 60 of which were men. Mean ages among men and women were 43.3 years old $( \pm 22.1)$ and 40.2 years old $( \pm 18.6)$, respectively. They utilized the same portable equipment for the measurement of PNIF used in the present study and the participants performed three measurements, the highest value of which was also chosen for analysis. The mean values of PNIF were $143 \mathrm{~L} / \mathrm{min}$ (SD \pm 48.6) and 121.9 L/min (SD \pm 36.6$)$ in men and women, respectively. The variables evaluated were age, height, and gender. In contrast to the adolescent and pediatric population, the results demonstrate a decrease of the PFIN with age. Similar to our findings, the researchers reported a slight gender difference, with higher values in men. Only Caucasian volunteers were assessed.

Recently, Klossek et al. evaluated 234 French subjects aged from 17 to 84 years old ${ }^{(17)}$. The same portable equipment for the measurement of PNIF was used, but the authors did not perform multivariate analysis. The mean values of PNIF were 104.6 L/min (SD \pm 54.8$)$ and $80.8 \mathrm{~L} / \mathrm{min}(\mathrm{SD} \pm 33.4)$ in men and women, respectively. Lower values found compared to Ottaviano study may be attributed to methodological issues differences. On the other hand, as found by Ottaviano et al., a slight but non significant tendency to reduction with age had been observed. The authors concluded that PNIF measurement is a reliable and simple technique for evaluation of maximal inspiratory nasal flow.

Papachristou et al. studied 3170 Greek children and adolescents from six to 18 years old and presented mean values of PNIF with 95\% confidence intervals for boys and girls according to their age ${ }^{(16)}$. PNIF measurements were performed with a Youlten Peak flow meter after a normal expiration and not from residual capacity as Ottaviano et al. and the present study performed. Values reported by Papachristou et al. were slightly higher. For example, mean PNIF of a boy aged eight years old was $110,91 / \mathrm{min}(\mathrm{SD} \pm 29.5$ ) whereas according to our study

* BMI: Body mass index. 


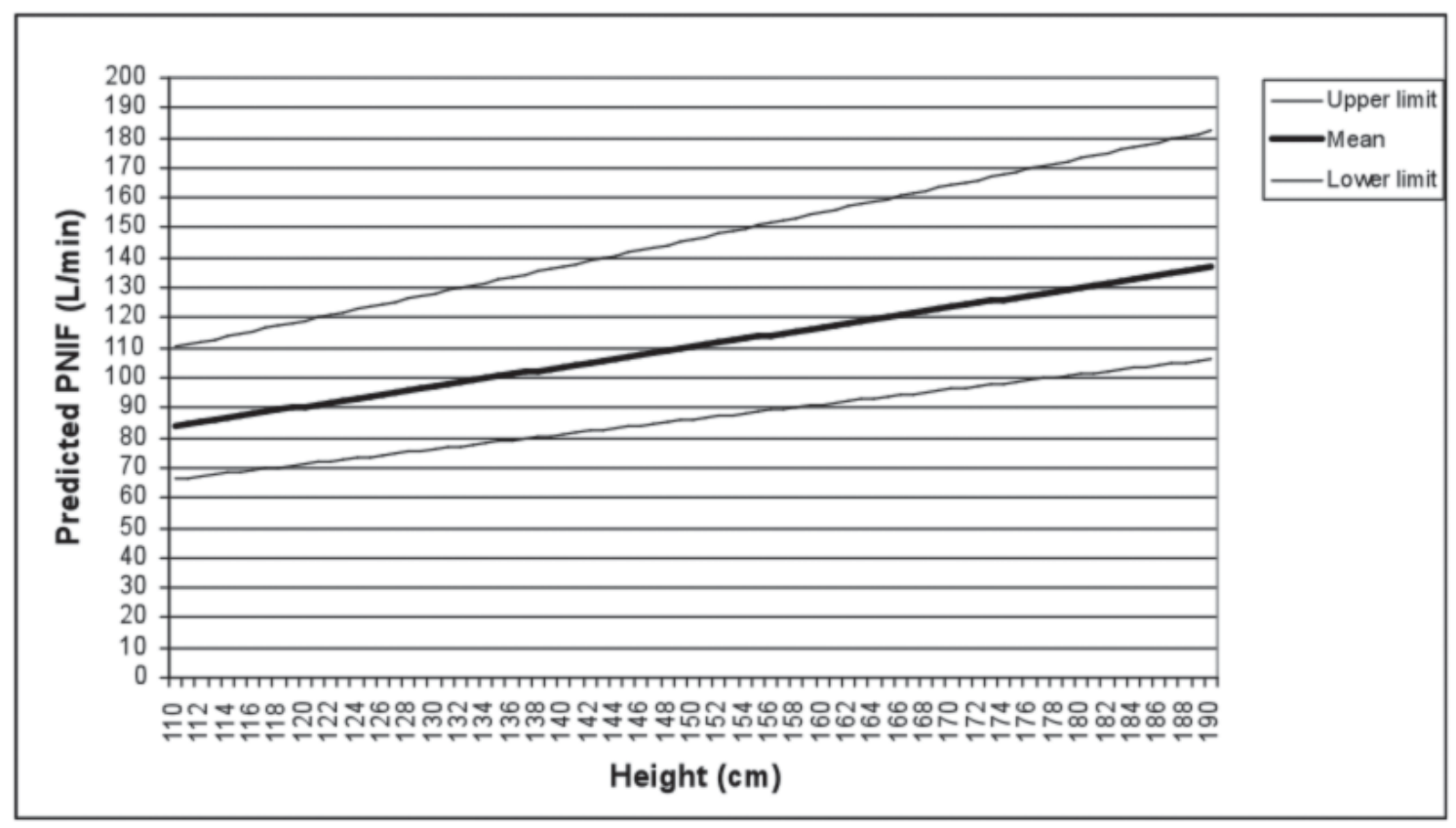

Figure 1. Peak nasal inspiratory flow (PNIF) predicted values for boys.

for a boy at this age, with a height of 128 centimeters, corresponding to the 50 percentile, the mean predicted value of PNIF is $95 \mathrm{~L} / \mathrm{min}$. This discrepancy is probably due to the different population studied and to different methods, but could also be attributed to the lack of multivariate analysis.

The fact that our study population is of mixed ethnicity, combining ancestors from Europe, Africa and native Brazilians, could be a strength, as we cannot define it exactly. Probably, the external validity of our observations may be better than studies performed in one population only.

PNIF is a simple, easily performed measurement and may be complementary to clinical evaluation of patients with allergic rhinitis. This is especially valid for the pediatric age group due to the subjective nature of the symptoms and the possibility that they can be underestimated, as patients frequently adapt themselves to the nasal obstruction secondary to chronic rhinitis. In a young adult population, Starling-Schwanz et al. found that PNIF was highly reproducible but not significantly correlated with rhinitis symptoms $(r=-0.11, p=0.057)^{(18)}$. Regarding individual variability of PNIF, Blomgren et al., found a substantial diurnal variation on PFIN in 20 healthy adults evaluated for 7 days ${ }^{(19)}$. Data on pediatric population are unavailable and future research in PNIF variability in children, especially in those with allergic rhinitis, should try to evaluate these questions. Until then, for the same patient it may be advisable to perform PNIF measurement at the same period of the day for appropriate comparisons.

The reported PNIF reference values for subjects older than 8 years old combined with the feasibility of such measure may facilitate the assessment of nasal obstruction by pediatricians, ENT specialists, allergists and general practitioners. Moreover, PNIF may be useful to motivate patients adapted to nasal obstruction to pay attention to their problem and improve adherence, as much as spirometric parameters and measurements of peak expiratory flow used for asthmatic patients contribute to the assessment of the level of control and treatments choice.

In conclusion, the equations of the final regression model resulted in a simple formula to obtain reference values of PNIF for subjects aged from 8 to 15 years old. We present reference curves of PNIF for boys and girls, a test easily performed in the doctors office, which may be as useful for chronic rhinitis as the peak expiratory flow measurements are to evaluate patients with asthma.

\section{ACKNOWLEDGMENTS}

We thank José Miguel Chatkin, Denise Utsch, Ricardo de Correia, Sérgio Amantéa for reviewing the original version of the manuscript.

\section{CONFLICT OF INTEREST}

There are no competing interests for any of the authors. 


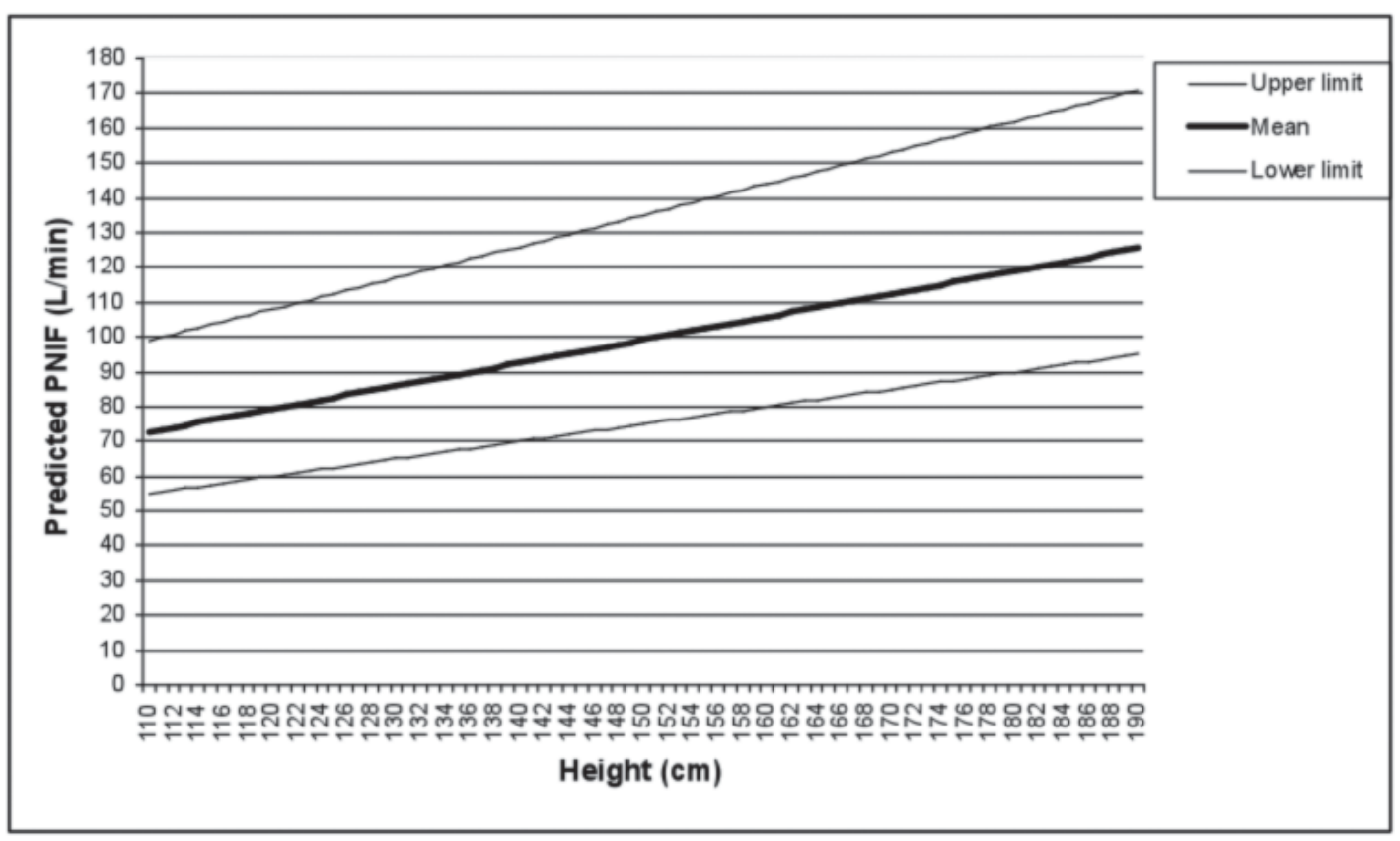

Figure 2. Peak nasal inspiratory flow (PNIF) predicted values for girls.

\section{REFERENCES}

1. Asher MI, Montefort S, Bjorksten B, et al. ISAAC Phase Three Study Group. Worldwide time trends in the prevalence of symptoms of asthma, allergic rhinoconjunctivitis, and eczema in childhood: ISAAC Phases One and Three repeat multicountry crosssectional surveys. Lancet. 2006; 368: 733-743.

2. Bousquet J, Khaltaev N, Cruz AA, et al. Allergic Rhinitis and its Impact on Asthma (ARIA) 2008 update. Allergy. 2008; 63: Suppl. 86, 8-160.

3. Canonica GW, Bousquet J, Mullol J, Scadding GK, Virchow JC. A survey of the burden of allergic rhinitis in Europe. Allergy. 2007; 85: 17-25.

4. Wilson A, Dempsey OJ, Sims EJ, Coutie WJR, Paterson MC, Lipworth BJ. Evaluation of treatment response in patients with seasonal allergic rhinitis using domiciliary nasal peak flow. Clin Exp Allergy. 2000; 30: 833-838.

5. Wilson AM, Dempsey OJ, Sims EJ, Lipworth BJ. A comparison of topical budesonide and oral montelukast in seasonal allergic rhinitis and asthma. Clin Exp Allergy. 2001; 31: 616-624.

6. Nathan RA, Eccles R, Howarth PH, Steinsvag SK, Togias A. Objective monitoring of nasal patency and nasal physiology in rhinitis. J Allergy Clin Immunol. 2005, 115: 442-459.

7. Chan KO, Huang ZI, Wang DY. Acoustic rhinometric assesment of nasal obstruction after treatment with fluticasone propionate in patients with perennial rhinitis. Auris Nasus Larynx. 2003; 30: 379-383

8. Jones AS, Viani L, Phillips DE, Charters P. The objective assessment of nasal patency. Clin Otolaryng. 1991; 16: 206-211.

9. Hilberg O. Objective measurement of nasal airway dimensions using acoustic rhinometry: methodological and clinical aspects. Allergy. 2002; 57 Suppl 70: 5-39.

10. Clement PA, Gordts F. Standardisation Committee on Objective Assessment of Nasal Airway, IRS, and ERS. Consensus report on acoustic rhinometry and rhinomanometry. Rhinology. 2005; 43: $169-179$.

11. Holmstron M, Scadding GK, Lund VJ, Darby YC. Assessment of nasal obstruction. A comparison between rhinomanometry and nasal inspiratory peak flow. Rhinology. 1990; 28: 191-196.
12. Wihl JA, Malm L. Rhinomanometry and nasal peak expiratory and inspiratory flow rate. Ann Allergy. 1988; 61: 50-55.

13. Frølund L, Madsen F, Mygind N, Nielsen NH, Svendsen UG, Weeke B. Comparison between different techniques for measuring nasal patency in a group of unselected patients. Acta Otolaryngol. 1987; 104: 175-179.

14. Ottaviano G, Scadding GK, Coles S, Lund VJ. Peak nasal inspiratory flow:normal range in adult population. Rhinology. 2006; 44: 32-35.

15. Prescott CA, Prescott KE. Peak nasal inspiratory flow measurements: an investigation in children. Int J Pediatr Otorhinolaryngol. 1995; 32: 137-141.

16. Papachristou A, Bourli E, Aivazi D, et al. Normal peak nasal inspiratory flow rate values in Greek children and adolescents. Hippokratia. 2008; 12: 94-102.

17. Klossek JM, Lebreton JP, Delagranda A, Dufour X. PNIF measurement on healthy French population. A prospective study about 234 patients. Rhinology. 2009; 47: 389-392.

18. Starling-Schwanz R, Peake HL, Salome CM, et al. Repeatability of peak nasal inspiratory flow measurements and utility for assessing the severity of rhinitis. Allergy. 2005; 60: 795-800.

19. Blomgren K, Simola M, Hytönen M, Pitkäranta A. Peak nasal inspiratory and expiratory flow measurements-practical tools in primary care? Rhinology. 2003; 41: 206-210.

Cássio da Cunha Ibiapina

Departamento de Pediatria da Faculdade de Medicina da Universidade Federal de Minas Gerais.

Avenida Professor Alfredo Balena, 190 / Sala 267

30130-100 Belo Horizonte

Brazil

Tel: + 55-31-3409 9772 